\title{
PROMOVENDO A COMPREENSÃO DA COMPOSIÇÃO ADITIVA EM CRIANÇAS SURDAS
}

\author{
Terezinha Nunes* \\ PETER BRYANT ${ }^{* *}$ \\ Deborah Evans ${ }^{* * *}$ \\ DANIEL BELL ${ }^{* * * *}$ \\ DARCY HALLETT ${ }^{* * * *}$
}

RESUMO: O estudo tem como objetivo analisar a compreensão da composição aditiva dos números em crianças surdas. Este artigo descreve dois estudos que utilizaram a Tarefa de Compra de Nunes e Schliemann (1990) para investigar a compreensão da composição aditiva em crianças no contexto de contar dinheiro. No primeiro estudo, comparamos a compreensão da composição aditiva em crianças surdas à de crianças ouvintes da mesma idade. No segundo estudo, realizamos uma breve intervenção para avaliar a possibilidade de melhorar sua compreensão de composição aditiva. Concluímos que intervençôes ainda que breves, mas teoricamente significativas e claramente direcionadas, podem ser usadas para melhorar o desempenho das crianças surdas nas tarefas que avaliam a composição aditiva.

Palavras-chave: Composição aditiva. Crianças surdas. Número. Contagem.

* Departamento de Educação, Oxford University - Oxford (Reino Unido).

** Departamento de Educação, Oxford University - Oxford (Reino Unido).

*** Departamento de Educação, Oxford University - Oxford (Reino Unido).

**** Departamento de Engenharia Mecânica e Ciências Matemáticas, Oxford Brookes University (Reino Unido).

***** Departamento de Psicologia, Memorial University - Newfoundland (Canadá).

Contato com os autores: <terezinha.nunes@education.ox.ac.uk>

Cad. Cedes, Campinas, v. 33, n. 91, p. 319-332, set.-dez. 2013

Disponível em <http://www.cedes.unicamp.br> 


\title{
Promoting THE COMPREHENSION OF ADDITIVE COMPOSITION BY DEAF CHILDREN
}

\begin{abstract}
This study aims at analyzing the comprehension of additive composition of number by deaf children. This article describes two studies that use the Purchasing Task from Nunes and Schliemann (1990) to investigate the perception of additive composition by children in the context of counting money. In the first study, we compared the comprehension of the concept by deaf children and hearing children of the same age. In the second study, we carried out a brief intervention to evaluate the possibility of enhancing deaf children's apprehension of the concept. We concluded that the interventions, even brief ones, but theoretically meaningful and clearly directed, can be used to improve the performance of deaf children in tasks that evaluate additive composition.
\end{abstract}

Key words: Additive Composition. Deaf children. Numbers. Counting.

\section{Quadro teórico}

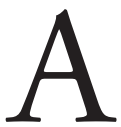

prender a usar números naturais é semelhante a aprender um idioma. Suponha que Linda, de 4 anos de idade, está numa pracinha e sua amiga Susana aponta para um menino e diz: "Aquele menino é meu irmão". Linda, sem dúvida, vai poder apontar para o menino e dizer para sua mãe: "Aquele menino é irmão de Susana”. Mas isso não é garantia de que ela entenda o significado da palavra "irmão". Por exemplo, se Susana apontar para outra menina na mesma pracinha e disser que aquela menina é sua irmã, não podemos ter certeza de que Linda vai chegar à conclusão de que a menina e o menino são irmãos. Essa inferência depende da compreensão de relações de parentesco; as palavras "irmão" e "irmã " se referem a classes definidas por relações. A fim de compreender a palavra irmão, precisamos entender um conjunto de relações de parentesco, como "pai de" e "mãe de". Aprender números naturais é, até certo ponto, semelhante. A fim de compreender o significado de "cinco", não é suficiente ser capaz de contar um conjunto de itens e dizer: "existem cinco". A compreensão do significado dos números é definida pela capacidade da criança de estabelecer conexões entre os nomes de números e um sistema de relações entre quantidades, que dão significado aos números. Por exemplo, se alguém dividir um pacote de doces 
e der quantidades iguais para duas crianças, basta contarmos o número de doces que uma delas ganhou e saberemos, por inferência, quantos doces a outra tem.

Piaget (1952) argumentou que não se pode dizer que alguém compreenda o que significa a palavra cinco se não souber que cinco é igual a quatro mais um ou três mais dois. Esse aspecto da compreensão do número chama-se composição aditiva de número e é um fator importante na compreensão das relaçôes entre os números. Até mesmo os críticos mais severos da teoria de Piaget concordam que a composição aditiva é central à compreensão da cardinalidade (por exemplo, LE CORRE; CAREY, 2007; RIPS; ASMUTH; BLOOMFIELD, 2006, 2008).

A composição aditiva é central à compreensão de qualquer sistema de numeração com uma base. O sistema de base-10, por exemplo, nos libera de ter que lembrar as palavras de número indefinidamente e em uma ordem fixa ao contar. Em português, por exemplo, precisamos aprender os rótulos numéricos de 1 a 20, bem como os rótulos para as dezenas (30,40, 50 etc.) e as palavras cem, mil e milhão. Se soubermos essas 31 palavras e compreendermos a composição aditiva e as regras de combinação para formar novos rótulos numéricos, podemos gerar os nomes de números até 999 milhões 999 mil e 999. Esse número de palavras é muito maior do que o que nossa capacidade de memória nos permite memorizar numa ordem fixa.

A composição aditiva também é fundamental para a compreensão do sistema hindu-arábico de valor de lugar que usamos para escrever os números: 127 , por exemplo, significa $100+20+7$. A composição aditiva igualmente é central à nossa capacidade de contar dinheiro usando notas e moedas de diferentes valores. Quando temos, por exemplo, uma moeda de 10 centavos e cinco moedas de 1 centavo, só podemos obter o valor total por contagem se entendermos composição aditiva.

Dada a importância da composição aditiva de número, é surpreendente que existam tão poucos estudos sobre a compreensão da composição aditiva tanto com crianças ouvintes como com crianças surdas. Nunes e Schliemann (1990) desenvolveram uma Tarefa de Compra para investigar a compreensão das crianças na composição aditiva no contexto de contagem de dinheiro. Essa tarefa inclui alguns itens de controle, que avaliam a habilidade de contagem das crianças usando apenas moedas 
de 1 centavo, e alguns itens de composição aditiva, em que as crianças são convidadas a combinar moedas de 1 centavo com moedas de outros valores - por exemplo, moedas de 5, 10 ou 20 centavos. Usamos esta Tarefa de Compra em dois estudos com crianças surdas. No primeiro, comparamos a compreensão das crianças surdas de composição aditiva à de crianças ouvintes da mesma idade. No segundo, realizamos uma breve intervenção para avaliar a possibilidade de melhorar sua compreensão da composição aditiva.

Estudo 1: O nível de conhecimento da composição aditiva entre crianças surdas

\section{Método}

Participaram do estudo 28 crianças surdas e 77 ouvintes que estavam no primeiro ano escolar. Todas as crianças que participaram eram de escolas estaduais; as crianças ouvintes foram recrutadas de duas escolas e as crianças surdas de seis, localizadas em Oxford ou Newbury (Inglaterra). Todas essas escolas atendem a crianças de vários níveis socioeconômicos, sendo sua clientela diversificada. Os níveis de perda auditiva das crianças surdas foram perda moderada $(n=3)$, grave $(n=7)$ e profunda $(n=18)$; 11 crianças tinham recebido implantes cocleares e sua perda é estimada entre moderada e profunda. A média de idade das crianças ouvintes foi 6 anos e 2 meses e das crianças surdas 6 anos e 5 meses. Esta diferença na média de idade não foi estatisticamente significativa.

\section{Medidas}

Neste estudo, utilizamos como avaliação da capacidade cognitiva das crianças o subteste de matrizes da Escala Britânica de Habilidades Cognitivas (BAS), que é uma medida de habilidades não verbais, e a Tarefa de Compra. Na tarefa de matrizes da BAS, são mostradas às crianças matrizes com células organizadas em linhas e colunas. Uma célula da matriz está vazia enquanto as outras estão preenchidas com figuras. A Figura 1 apresenta um item semelhante aos usados nessa tarefa; por razóes de direitos autorais, não se pode incluir um item da tarefa. As crianças devem escolher, entre as várias alternativas oferecidas, a que melhor completa a matriz. 


\section{Figura 1}

Um item construído para ilustrar os itens da tarefa de matrizes da Escala Britânica de Habilidades Cognitivas
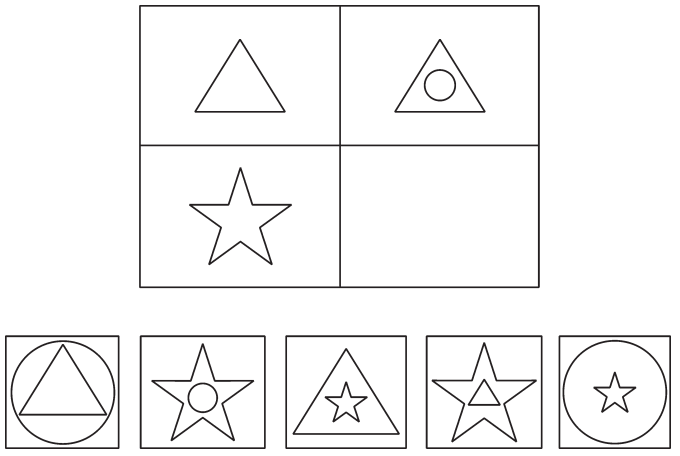

Na Tarefa de Compra, as crianças são convidadas a brincar com o pesquisador de compra e venda dos objetos disponíveis sobre a mesa. A fim de apresentar a tarefa, convidamos as crianças a identificar o valor das moedas. Em seguida, pede-se às crianças que identifiquem que objetos querem comprar e façam o pagamento usando apenas moedas de 1 centavo. $\mathrm{O}$ desempenho das crianças nesses itens permite avaliar se elas sabem contar até vinte, que ultrapassa o maior valor utilizado na tarefa para avaliar a composição aditiva. Todos os itens que avaliam a composição aditiva devem estar dentro dos limites da habilidade de contagem da criança.

Nos testes de composição aditiva, apresentamos às crianças moedas de 1 centavo em combinação com moedas de 5 ou de 10 centavos; cada uma dessas combinaçóes de moedas de 1 centavo com outra de maior valor é apresentada separadamente. Foram usadas cinco moedas de 1 centavo em combinação com uma moeda de 5 centavos para o pagamento de valores entre 6 e 9 centavos; para o pagamento de valores entre 11 e 19, a criança dispunha de uma moeda de 10 e nove moedas de 1 centavo. Como a Linguagem dos Sinais Britânica (BSL) tem um sistema de contagem de base mista, o qual utiliza cinco e dez como base, todos os itens estão relacionados com os processos de agrupamento na BSL. Usamos seis itens de composição aditiva, três combinações envolvendo moedas de $5 \mathrm{c}$ e 1c e três envolvendo combinações de moedas de 10c e 1c. Se a criança 
não conseguisse contar o dinheiro em qualquer dos itens, a pesquisadora demonstrava como fazer a contagem, apontando primeiro para a moeda de maior valor - por exemplo, a moeda de 5 centavos -, dizia o seu valor e, em seguida, apontava para a primeira das moedas de 1 centavo dando continuidade à sequência. A criança era solicitada a completar a contagem para descobrir quanto havia de dinheiro no total. As crianças recebiam dois pontos para cada item alcançado sem demonstração, um ponto se completassem a contagem corretamente depois da demonstração, e 0 ponto se não contassem o dinheiro corretamente, mesmo depois da demonstração. Os erros típicos consistiam em dizer os totais separadamente (por exemplo, dizendo "cinco e três", quando a criança tem uma moeda de 5 centavos e três de 1 centavo) ou contando todas as moedas como se fossem de 1 centavo (no mesmo exemplo, a criança contaria os 5 centavos como 1 centavo e diria que ela tem 4 centavos).

Todas as tarefas foram administradas individualmente por um pesquisador na linguagem usada pela criança na escola (inglês ou BSL). As respostas das crianças foram pontuadas independentemente da linguagem usada.

\section{Resultados}

Todas as crianças identificaram corretamente as moedas e resolveram corretamente os itens de contagem de dinheiro quando as moedas utilizadas eram apenas de 1 centavo. A média de respostas corretas das crianças ouvintes na tarefa de matrizes da BAS foi 9,1 e a média das crianças surdas foi 6,32. Essa diferença de desempenho foi estatisticamente significativa de acordo com um teste $t$ para amostras independentes $(\mathrm{t}=3,62$; $\mathrm{df}=$ $105<0,001)$. Em virtude desta diferença significativa na tarefa de matrizes, a comparação entre o desempenho das crianças surdas e ouvintes na tarefa de composição aditiva foi realizada utilizando a análise de covariância, controlando-se o desempenho no subteste BAS-matrizes.

Mesmo após o controle do desempenho no subteste BAS-matrizes, o desempenho das crianças ouvintes superou o das crianças surdas na tarefa de composição aditiva: as médias ajustadas, controlando o desempenho no teste de BAS-matrizes, foram: 10,91 para as crianças ouvintes e 3,47 para as crianças surdas (pontuação máxima: 12). 


\section{Conclusão e discussão}

A maioria das crianças ouvintes começa a escola com uma boa base para compreender o sistema de numeração decimal e sua escrita usando o valor posicional, pois seu desempenho na Tarefa de Compra demonstra sua compreensão da composição aditiva. Em contraste, a maioria das crianças surdas não está preparada para compreender o sistema de numeração e a escrita de números. Este resultado é particularmente importante porque as crianças surdas contaram corretamente em todos os itens em que as moedas eram todas de 1 centavo. Esse desempenho em contagem causa uma falsa impressão de competência; embora as crianças saibam contar, demonstram não compreender bem o sistema de numeração por não conseguirem um bom desempenho na tarefa de composição aditiva. Como as crianças surdas contam corretamente as moedas de 1 centavo, sua dificuldade nos testes de composição aditiva não pode ser atribuída ao desconhecimento da sequencia numérica: elas sabiam a sequência numérica, mas não entendiam o significado relacional dos números definido na tarefa de composição aditiva.

Uma explicação verossímil para sua dificuldade na Tarefa de Compra seria uma possível falta de oportunidades para as crianças surdas em lidar com o dinheiro. No entanto, esta explicação não é muito plausível, uma vez que todas as crianças mostraram reconhecer o valor das moedas na apresentação inicial da tarefa. Portanto, é pouco provável que sua dificuldade com a composição aditiva seja devida à sua falta de experiência com moedas.

Uma segunda explicação admissível para a diferença observada entre crianças ouvintes e surdas seria um possível atraso cognitivo das crianças surdas. No entanto, como usamos a análise de covariância na comparação dos resultados na tarefa de composição aditiva, controlando estatisticamente seu desempenho no subteste BAS-matrizes, que tem uma correlação significativa relacionada com a aprendizagem de matemática (NUNES et al., 2009), não é provável que a diferença entre crianças ouvintes e surdas possa ser explicada pelas diferenças na capacidade cognitiva.

Embora não seja possível explicar esta diferença entre os dois grupos de crianças, pesquisas anteriores mostram que a dificuldade com composição aditiva pode interferir negativamente na aprendizagem de matemática na escola. Usando um estudo longitudinal, Nunes et al. (2007) mostraram 
que a composição aditiva avaliada no primeiro ano escolar é um bom preditor da aprendizagem matemática das crianças ouvintes no fim do segundo ano escolar. Em um segundo estudo, os mesmos pesquisadores mostraram que uma intervenção que promova o progresso das crianças na composição aditiva tem um impacto positivo sobre o seu aprendizado de matemática. Assim, no estudo relatado a seguir, investigamos se é possível melhorar a compreensão das crianças surdas de composição aditiva através da instrução.

Estudo 2: os efeitos de um programa de ensino

\section{Método}

Participaram deste estudo 22 crianças surdas que estavam no primeiro ou no segundo ano em escolas em Oxford (Inglaterra) ou Londres. As crianças frequentavam ou uma escola regular (cinco escolas) ou uma escola especial para surdos. Os níveis de perda auditiva foram moderado $(\mathrm{n}=3)$, grave $(n=5)$ ou profundo $(n=14) ; 11$ crianças tinham implantes cocleares e seu nível de perda auditiva foi estimado entre severo e profundo. A idade média dos participantes foi 6 anos e 10 meses.

\section{Plano do estudo}

O estudo incluiu um pré-teste, uma breve intervenção, um pós-teste imediato e um pós-teste tardio, administrado entre duas e quatro semanas após o pós-teste imediato. As crianças de cada classe de participantes foram aleatoriamente designadas para um grupo de intervenção ou de controle. As crianças do grupo de intervenção resolveram uma série de problemas de Tarefa de Compra durante a intervenção. As crianças do grupo de controle resolveram um conjunto de tarefas matemáticas que focava a relação inversa entre adição e subtração. A distribuição aleatória aos grupos e o uso de um grupo de controle ativo que resolvia tarefas de matemática, as quais não deveriam facilitar a compreensão da composição aditiva, compõem um modelo experimental rigoroso, que exclui a possibilidade de várias explicações alternativas para o progresso das crianças na tarefa, como a oportunidade de trabalhar mais com números e maior familiaridade com os pesquisadores. Todas as tarefas foram administradas individualmente por 
um pesquisador na linguagem utilizada pela criança na escola (inglês ou BSL). A intervenção foi realizada durante duas sessões de aproximadamente quarenta minutos cada.

\section{Medidas}

Os pré e pós-testes eram idênticos e incluíram a Tarefa de Compra (descrita no Estudo 1), que foi administrada sem a demonstração adicional fornecida no primeiro Estudo, e uma Tarefa de Transferência, adaptada de um estudo realizado por Miura et al. (1988). Nesta Tarefa de Transferência, foram dadas às crianças duas barras de dez blocos Unifix, que representam dezenas, e vinte blocos equivalentes à unidade. Pediu-se às crianças que dessem ao pesquisador 11, 16 e 13 blocos. Nosso objetivo nessa Tarefa de Transferência foi avaliar o uso da composição aditiva pelas crianças em uma tarefa com a qual não tiveram familiaridade durante a intervenção. Se as crianças utilizassem espontaneamente a composição aditiva numa tarefa nova, elas usariam uma barra de dez blocos e uma, seis e três unidades, respectivamente, para formar 11, 16 e 13 blocos. Embora esse procedimento não fosse requerido, pois as crianças dispunham de vinte blocos unitários e poderiam realizar a tarefa corretamente usando apenas os blocos unitários, o uso das barras de dez ilustraria sua compreensão da eficiência da composição aditiva. As respostas foram avaliadas atribuindo-se um ponto quando as crianças usavam uma das barras de dez blocos e zero ponto se não a utilizassem, ainda que elas tivessem contado os blocos corretamente.

Todas as crianças participaram em todos os testes, independentemente do seu desempenho.

\section{Intervenção}

Trabalhos anteriores (por exemplo, STEFFE et al., 1983) mostraram, em tarefas de adição, a importância para o progresso das crianças na compreensão do número cardinal na habilidade de contar a partir de uma quantidade já identificada, ao invés de contar todos os itens. Em tarefas de adição, pode-se pedir às crianças que indiquem quantos blocos teremos, por exemplo, se juntarmos 13 blocos vermelhos com seis blocos azuis. Como as crianças no primeiro ano escolar não sabem responder a uma pergunta 
com este nível de dificuldade, seu procedimento será sempre formar conjuntos de blocos e somar. No entanto, esse procedimento varia: algumas crianças formam apenas um conjunto de seis e contam esse conjunto a partir de 14, dando sequência à contagem dos 13 blocos que formariam o primeiro grupo. Em contraste, outras crianças formam dois conjuntos, um com 13 e outro com seis blocos, e contam todos os blocos a partir de um. Em nosso estudo, a intervenção foi projetada para ajudar as crianças a adotarem procedimentos de contar o dinheiro na Tarefa de Compra a partir de uma quantidade já identificada pelas moedas de 2, 5 ou 10 centavos.

Durante a intervenção, quando uma tarefa era apresentada e a criança não conseguia resolvê-la, o pesquisador pedia à criança para lhe mostrar com os dedos o valor da moeda de maior valor (dois, cinco ou dez). A seguir, o pesquisador apontava para os dedos da criança enquanto dizia o número de dedos sem contá-los um por um, e dava sequência à contagem do dinheiro a partir desse número. $\mathrm{O}$ pesquisador encorajava a criança a terminar a contagem do dinheiro e, finalmente, perguntava-lhe qual era a quantidade total de dinheiro.

Os itens usados durante a intervenção continham combinações de moedas de 2, 5, 10 e 20 centavos com moedas de 1 centavo. Para os itens em que se usava uma moeda de 20 centavos, a demonstração consistia em apontar para a moeda dizendo "vinte", e depois contando em sequência, enquanto o pesquisador apontava para as moedas de 1 centavo. Depois destas primeiras tentativas em que se usavam moedas de 1 centavo em combinação com apenas uma moeda de outro valor (12 no total), a criança era convidada a contar combinaçôes de moedas que incluíam mais de uma moeda com valor superior a 1 centavo (por exemplo, duas moedas 2 centavos; uma de 5 centavos e uma de 2 centavos).

O grupo de controle também trabalhou individualmente com um dos pesquisadores em uma tarefa matemática. Esta tarefa envolveu o raciocínio sobre a relação inversa entre adição e subtração e não se relacionava diretamente à composição aditiva. As crianças usaram blocos e outros objetos para resolver problemas durante esta intervenção, mas não trabalharam com contagem de dinheiro. Esperava-se que o grupo de controle se beneficiasse significativamente da participação no estudo, mas seu progresso seria especificamente na compreensão da relação inversa entre adição e subtração, o que de fato ocorreu. Os resultados do ensino da relação inversa entre adição e subtração foram relatados por Nunes et al. (2008). 


\section{Resultados}

Foram utilizadas duas análises de covariância para comparar o grupo de intervenção com o grupo de controle. Na primeira análise, avaliou-se o efeito da intervenção sobre a Tarefa de Compra e na segunda foi avaliado o efeito sobre a Tarefa de Transferência. O controle usado na análise de covariância foi o número de respostas corretas na tarefa equivalente no pré-teste (ou seja, a Tarefa de Compras ou a Tarefa de Transferência). Os resultados no pré-teste, pós-teste imediato e pós-teste tardio estão apresentados na Tabela 1. As médias apresentadas para os pós-testes são as médias ajustadas, controlando-se o desempenho no préteste. Pode-se observar na Tabela 1 que o grupo de intervenção mostra progresso claro na Tarefa de Compra, sendo que a média ainda aumenta entre o pós-teste imediato e o deferido. Em contraste, as médias do grupo de controle em ambos os pós-testes são muito semelhantes à média observada no pré-teste.

\section{Tabela 1}

Médias nas Três Ocasiōes para os Grupos de Intervenção e Controle

\begin{tabular}{lccc}
\hline Grupo & Pré-teste & Pós-teste imediato & Pós-teste tardio \\
\hline Controle & & & \\
Tarefa de Compra (max. 6) & 2,1 & 2,0 & 2,2 \\
Transferência (max. 3) & 0,8 & 0,9 & 1,2 \\
\hline Intervenção & & & \\
Tarefa de Compra (max. 6) & 1,0 & 5,1 & 4,6 \\
Transferência $(\max .3)$ & 0,9 & 2,0 & 1,4 \\
\hline
\end{tabular}

As diferenças entre os grupos foram significativas em ambas as medidas no pós-teste imediato: para a Tarefa de Compra, F $(1,25)=29,3$, $\mathrm{p}<0,001$, para a Tarefa de Transferência, $\mathrm{F}(1,24)=5,07 ; \mathrm{p}<0,05)$. Os tamanhos do efeito ( $\mathrm{d}$ de Cohen) foram de 1,3 Desvio Padrão (DP) para a Tarefa de Compra e 0,9 DP para a Tarefa de Transferência. Ambos os efeitos são considerados fortes. No pós-teste tardio, apenas a diferença no desempenho de Tarefas de Compra foi significativa: $\mathrm{F}(1,24)=10,07, \mathrm{p}=$ 0,004; $\mathrm{d}$ de Cohen = 0,97 SD, que é um efeito forte. 


\section{Conclusões e implicações educacionais}

Esta investigação mostrou pela primeira vez que, em comparação com crianças ouvintes frequentando o mesmo ano na escola, as crianças surdas estão atrasadas em sua compreensão da composição aditiva. Além disso, mostrou-se também pela primeira vez que mesmo um breve período de ensino pode ser eficaz em melhorar o seu desempenho. $O$ poder de sua nova compreensão de número foi documentado de duas maneiras. Em primeiro lugar, o seu desempenho na tarefa de composição aditiva não deteriorou significativamente no período do pós-teste imediato até o pós-teste tardio. Em segundo lugar, as crianças mostraram progresso significativo também na tarefa de transferência, que não tinham visto durante a intervenção. Como a tarefa de transferência usou uma metodologia em que a resposta poderia ser baseada em dois procedimentos alternativos, sendo a resposta mais avançada opcional (ou seja, as crianças poderiam fornecer o número correto de blocos usando apenas as unidades), essa transferência demonstra a compreensão da economia de tempo e esforço quando a criança usa uma barra de dez para obter um número de blocos maior do que dez.

Pode parecer surpreendente que essa breve intervenção tenha sido eficaz, mas o poder da intervenção reside em sua qualidade, baseada simultaneamente numa análise teórica consistente e em resultados anteriores que mostraram sua adequação para as crianças surdas. Pesquisas anteriores demonstraram que as crianças compreendem a ideia de contar em sequência antes de entender a composição aditiva (NUNES; BRYANT, 1996). Foi também demonstrado que uma representação visual do valor indexado pela moeda usando os dedos, mostrada simultaneamente à apresentação da moeda, ajuda as crianças surdas a fazerem a ligação entre as duas representaçōes (NUNES, 2004). Provavelmente, o uso da habilidade visual das crianças surdas nesta intervenção permitiu a sua aprendizagem durante um período tão curto de tempo.

As crianças do grupo de intervenção não continuaram a ter um desempenho estatisticamente melhor do que o do grupo de controle na tarefa de transferência, mas não é possível concluir que o seu desempenho se deteriorou ao longo das semanas que separaram o pós-teste imediato do tardio. $\mathrm{O}$ uso de um paradigma opcional, em que as crianças podem dar uma resposta correta usando uma barra com dez blocos ou dez blocos unitários, não conectados em uma barra única, torna a interpretação do seu desempenho ambígua. Miura et al. (1988) usaram esta tarefa com sucesso para identificar as diferenças 
entre crianças norte-americanas de língua inglesa e crianças japonesas, que usam um sistema de contagem onde as dezenas são claramente indicadas: por exemplo, a palavra para "onze" é literalmente "dez-um", a palavra para "doze" é "dez-dois", a palavra para "vinte" é "dois-dez" e a palavra para "vinte e um" é "dois-dez-um". Esta transparência na relação entre rótulos numéricos e quantidade pode criar uma preferência para pensar em termos de composição aditiva e usar a barra de dez blocos mesmo num paradigma opcional. Ocorreu-nos posteriormente que poderíamos ter usado na tarefa de transferência um número de blocos unitários que não permitisse o sucesso sem a utilização da barra de dez blocos. Por exemplo, poderíamos ter solicitado às crianças 18 blocos e dado a elas uma barra de dez e 11 blocos unitários. Se a criança tentasse resolver a tarefa usando apenas blocos unitários, ela não teria os 18 blocos, e assim poderia concluir que a tarefa só seria resolvida corretamente se ela usasse uma barra de dez blocos, ou seja, usasse a composição aditiva. Isso poderia ter permitido que as crianças do grupo de intervenção aplicassem o seu conhecimento recém-adquirido de composição aditiva na tarefa de transferência.

Concluímos que as intervenções teoricamente significativas e bem focadas em seu objetivo podem ser usadas para melhorar o desempenho das crianças surdas em tarefas que avaliam a composição aditiva. Espera-se que, ao entrar na escola, tais intervenções beneficiem a compreensão, pelas crianças, de aspectos fundamentais do conceito de cardinalidade. Essas intervençôes poderiam eventualmente promover uma melhora no aprendizado da matemática entre os alunos surdos, que atualmente apresentam um atraso (TRAXLER, 2000) em matemática. Esse atraso não é esperado, tendo em vista que a inteligência não verbal, que está correlacionada à aprendizagem em matemática, não mostra diferenças entre surdos e ouvintes (BRADEN, 1994).

\section{Referências}

BRADEN, J.P. Deafness, deprivation and IQ. New York: Plenum, 1994.

LE CORRE, M.; CAREY, S. One, two, three, nothing more: an investigation of the conceptual sources of verbal number principles. Cognition, Amsterdam, v. 105, n. 2, p. 395-438, 2007.

MIURA, I.T. et al. Effects of language characteristics on children's cognitive representation of number: cross-national comparisons. Child Development, Chicago, v. 59, p. 1445-1450, 1988. 
NUNES, T. Teaching mathematics to deaf children. London: Whurr, 2004. NUNES, T.; BRYANT, P. Children doing mathematics. Oxford: Blackwell, 1996.

NUNES, T. et al. The contribution of logical reasoning to the learning of mathematics in primary school. British Journal of Developmental Psychology, Leicester, v. 25, p. 147-166, 2007.

NUNES, T. et al. Deaf children's understanding of inverse relations. In: MARSHARK M.; HAUSER, P.C. (Ed.). Deaf cognition: foundations and outcomes. Oxford: Oxford University, 2008. p. 201-225.

NUNES, T. et al. Deaf children's informal knowledge of multiplicative reasoning. Journal of Deaf Studies and Deaf Education, Oxford, v. 14, n. 2, p. 260-277, 2009.

PIAGET, J. The child's conception of number. London: Routledge, 1952.

RIPS, L.J.; ASMUTH, J.; BLOOMFIELD, A. Giving the boot to the bootstrap: how not to learn the natural numbers. Cognition, Amsterdam, v. 101, n. 3, p. B51-60, 2006.

RIPS, L.J.; ASMUTH, J.; BLOOMFIELD, A. Discussion: Do children learn the integers by induction? Cognition, Amsterdam, v. 106, p. 940-951, 2008.

STEFFE, L.P. et al. Children's counting types: philosophy, theory and application. New York: Praeger, 1983.

TRAXLER, C.B. The Stanford Achievement Test, 9th edition: National norming and performance standards for deaf and hard-of-hearing students. Journal of Deaf Studies and Deaf Education, v. 5, n. 4, p. 337-348, 2000.

Recebido em 30 de maio de 2013.

Aprovado em 30 de setembro de 2013. 